\title{
Epidemiological investigation of a fatal case of cholera in Japan by phenotypic techniques and pulsed-field gel electrophoresis
}

\author{
M. MATSUMOTO, M. SUZUKI, R. HIRAMATSU, M. YAMAZAKI, H. MATSUI, K. SAKAE, \\ Y. SUZUKI and Y. MIYAZAKI
}

Department of Microbiology, Aichi Prefectural Institute of Public Health, 7-6 Nagare Tsuji-machi Kita-ku, Nagoya 462-8576, Aichi, Japan

\begin{abstract}
A fatal case of cholera caused by Vibrio cholerae 01 El Tor serotype Ogawa occurred in Aichi Prefecture, Japan in 1995. The patient was identified locally, but the route of the infection was unknown. The causative isolate and 38 other domestic and imported $V$. cholerae $\mathrm{O1}$ isolates, obtained between 1984 and 1997, were analysed by prophage typing, antimicrobial susceptibility testing and pulsed-field gel electrophoresis (PFGE). This was done to determine whether the isolate from this case differed from others associated with either mild cholera infections or asymptomatic carriage, and to elucidate the route of infection. Cholera toxin (CT) from 37 toxigenic isolates was assayed semiquantitatively. The 39 isolates were divided into 12 temporary types in accordance with the results of the three typing techniques. The isolate from the fatal infection and nine other isolates were classified as temporary type IV. No difference in CT production was found between the isolate from the fatal case and the other 36 toxigenic isolates. Taken together, it is unlikely that a $V$. cholerae $\mathrm{O1}$ isolate of distinguishable type was responsible for the fatal illness. Temporary type IV isolates were frequently present in both domestic and imported cases from 1994 to 1997 in Aichi, but they did not emerge before 1993. These results suggest that a new clone was introduced after 1993 from overseas and then disseminated into Aichi, and this may have been an important step in triggering the fatal case of cholera.
\end{abstract}

\section{Introduction}

Vibrio cholerae $\mathrm{O} 1 \mathrm{El}$ Tor is responsible for the seventh cholera pandemic and has spread to Asia, Africa, Europe and Latin America [1]. In Japan, where cholera is relatively rare, so-called imported cases among travellers returning from foreign countries have gradually increased in recent years. In 1995, a large outbreak involving 278 cholera patients and 18 carriers occurred among travellers returning from sightseeing tours to Indonesia. Domestic cases, occurring among those who had not travelled abroad before the onset of the disease, have also increased in comparison with earlier years. In the past three decades, four indigenous large-scale outbreaks have occurred in Japan [2].

A fatal case of cholera caused by $V$. cholerae $\mathrm{O} 1 \mathrm{El}$ Tor serotype Ogawa was reported in Aichi Prefecture,

Received 31 Oct. 2000; revised version accepted 24 September 2001.

Corresponding author: Dr M. Matsumoto (e-mail: masakado_matsumoto@mail.pref.aichi.jp).
Japan in 1995. Such cases are rare in Japan and this was the first for 17 years. The patient was a healthy, middle-aged adult who had no apparent underlying disease and no history of overseas travel before the onset. The route of infection remained unclear in spite of an epidemiological study. The goals of the current study were to determine whether this fatal case of cholera was due to an isolate of $V$. cholerae $\mathrm{O} 1$ distinct from isolates of mild cholera infections and healthy carriers, and to elucidate the route of the infection. Phenotypic methods and pulsed-field gel electrophoresis (PFGE) were used to type $39 \mathrm{~V}$. cholerae $\mathrm{O} 1$ isolates obtained during 1984-1997 from domestic and imported cases. A semi-quantitative assay of the cholera toxin (CT) was done with 37 isolates.

\section{Materials and methods}

\section{Bacterial isolates}

Of $39 \mathrm{~V}$. cholerae $\mathrm{O} 1$ isolates examined, one was from a fatal case of cholera, 37 were from mild cholera 
infections (three were isolated from sewage of houses of patients with mild cholera) and one was from an asymptomatic carrier who came into contact with cholera patients. The isolates were obtained from 12 domestic cases, including the fatal infection, 24 imported cases and three cases of unknown origin before 1990. They are shown in Table 1. Twenty-nine were isolated in laboratories of this Institute or regional health centres in Aichi. Nine isolates from imported and sporadic cases in 1995 and one from a domestic case in 1995 were donated by Nagoya Airport Detached Office, Nagoya Quarantine Station, Aichi, and Tokyo Metropolitan Research Laboratory of Public Health, Tokyo, respectively.

\section{Plasmid DNA extraction}

Plasmid DNA was extracted according to a modified Kado method [3].

\section{Prophage typing}

Prophage typing was performed following previously established procedures $[4,5]$. V. cholerae O1 El Tor can be divided into three prophage types: Classic-Ubon is neither sensitive to nor produces $\kappa$-type phage; Celebes is not sensitive to but produces the phage; Celebes 'cured' is sensitive to, but does not produce, the phage.

\section{Antimicrobial susceptibility tests}

Antimicrobial susceptibility testing was performed with nine antibiotics by the agar dilution method [6]. The antibiotics used in this study and their MICs interpreted as resistance were as follows $(\mathrm{mg} / \mathrm{L})$ : ampicillin (100), chloramphenicol (12.5), gentamicin (16), kanamycin $(>100)$, nalidixic acid (32), norfloxacin (16), streptomycin $(>100)$, tetracycline (12.5) and trimethoprim (16) $[6,7]$. All antibiotics were purchased from Sigma.

\section{PFGE}

DNA for restriction endonuclease digestion and analysis by PFGE was prepared as described previously, with a minor modification [8]. The chromosomal DNA was digested with restriction endonucleases Not I and Sfi I (New England Biolabs, Beverly, MA, USA). DNA fragments were then separated by an LKB2015 Pulsaphor (Pharmacia LKB, Uppsala, Sweden) for $20 \mathrm{~h}$ at $200 \mathrm{~V}$ with pulsed times ranging from 5 to $50 \mathrm{~s}$ [9]. $\lambda$ DNA concatemers (Amersham Pharmacia Biotech, Buckinghamshire) were used as the size markers. Patterns of DNA fragmentations were assessed visually and distinct patterns were assigned an arbitrary designation. The interpretation of clonal relatedness was based on that proposed by Tenover et al. [10]. PFGE types that differed by two or three bands were considered to be closely related and were designated by a letter followed by arbitrary numbers. Strains that differed by four-to-six bands were considered to be possibly related, and those that differed by more than seven bands were considered to be different. The strains defined as possibly related and different were assigned different letters.

\section{Production of CT and detection of the gene}

Production of CT was evaluated by reversed passive latex agglutination (RPLA) (Denka Seiken, Tokyo, Japan) according to the manufacturer's instructions. A semi-quantitative assay of the CT was done with 37 toxigenic $V$. cholerae $\mathrm{O} 1$ isolates. The supernates were diluted two-fold serially to a final dilution range of $2^{1}-$ $2^{12}$ (2-4096). The highest dilution in which CT was detected was regarded as the amount (titre) of CT of each isolate. The presence or absence of the CT gene was detected by a PCR assay with TaKaRa Ex Taq and primers for the CT gene of $V$. cholerae (Takara Shuzo, Kyoto, Japan) according to the manufacturer's protocol. PCR mixtures were amplified on a Perkin Elmer GeneAmp PCR System 9600 (Perkin Elmer Japan, Chiba, Japan). Fifteen isolates obtained in the 1980s were

Table 1. V. cholerae $\mathrm{O} 1$ isolates used in this study

\begin{tabular}{|c|c|c|c|c|}
\hline $\begin{array}{l}\text { Domestic or } \\
\text { imported }\end{array}$ & $\begin{array}{l}\text { Outbreak or } \\
\text { sporadic }\end{array}$ & Estimated place of infection & $\begin{array}{l}\text { Year of } \\
\text { isolation }\end{array}$ & $\begin{array}{l}\text { Number of } \\
\text { isolates* }\end{array}$ \\
\hline \multirow[t]{2}{*}{ Domestic } & Outbreak & Unknown & 1989 & $5^{\dagger}$ \\
\hline & Sporadic & Unknown & $1993-1997$ & $7 *$ \\
\hline \multirow[t]{6}{*}{ Imported } & \multirow[t]{2}{*}{ Outbreak } & Taiwan & 1984 & $6^{\dagger}$ \\
\hline & & Indonesia & 1995 & $6^{\dagger}$ \\
\hline & \multirow[t]{4}{*}{ Sporadic } & China & 1987 & 1 \\
\hline & & Philippines & 1994 & 1 \\
\hline & & Vietnam and Hong Kong & 1995 & 1 \\
\hline & & Indonesia & 1995 & $9^{\S}$ \\
\hline Unknown & Sporadic & Unknown & Before 1990 & 3 \\
\hline Total & $\ldots$ & $\ldots$ & $\ldots$ & 39 \\
\hline
\end{tabular}


tested only by RPLA; the remaining 24 , isolated in the 1990 s, were tested by both methods.

\section{Results}

Of the $39 \mathrm{~V}$. cholerae O1 El Tor isolates, 34 were serotype Ogawa and 5, obtained from a domestic outbreak in 1989, were serotype Inaba. All but two imported cases in 1987 and a domestic case in Tokyo in 1995 were shown to be toxigenic by RPLA or PCR, or both. The results of PCR for the CT gene with 24 isolates obtained in the 1990s were consistent with those of RPLA assay. Plasmid analysis revealed that none of the 39 isolates carried plasmids. Two different random amplified polymorphic DNA (RAPD)-PCRs for typing the $39 \mathrm{~V}$. cholerae $\mathrm{O} 1$ isolates were performed with two distinct arbitrary primers at low annealing temperature. The sequences of the primers used were 5'-ACCTCGAGCA-3' and 5'-GGTGCGGGAA-3' [11, 12]. With the two PCR techniques, the 39 isolates were classified into two groups, i.e., 37 toxigenic isolates and 2 non-toxigenic isolates. The discriminatory power of plasmid analysis and RAPD-PCR was poor and thus the methods were not suitable for typing the $V$. cholerae O1 isolates examined.

Prophage typing classified the 39 isolates into three types. Celebes was dominant, and accounted for 25 isolates, followed by Classic-Ubon with eight and Celebes 'cured' with six. Twenty-eight isolates were susceptible to all nine antibiotics tested; however, 10 were resistant to streptomycin. Only one isolate, from a domestic case in 1993, showed resistance to both streptomycin and trimethoprim. The results of phenotypic analysis are summarised in Table 2.

PFGE analysis of the DNAs digested with Not I and $S f i$ restriction endonucleases generated eight and seven different PFGE patterns, respectively (Table 2, Fig. 1).
Three Not I-digested PFGE patterns (A, D and F) were further differentiated into two or three subtypes, although the other five PFGE patterns were not classified into subtypes. On PFGE analysis with $S f i$, PFGE pattern D had eight different subtypes, but the other six PFGE patterns were not subdivided. The subtypes of the NotI- or $S f i$ I-digested PFGE patterns were closely related to other subtypes, differing by only two or three bands, and showed considerable genetic homogeneity. Therefore, the subtypes with the same PFGE patterns were considered to be of the same origin and this study did not differentiate between them at this level. Ten PFGE combination patterns (AA-HD) were thus detected. The causative $V$. cholerae $\mathrm{O} 1$ isolate from the fatal case of cholera was classified into pattern CD. This pattern was detected in $21 \mathrm{~V}$. cholerae $\mathrm{O} 1$ isolates obtained between 1994 and 1997, including six sporadic isolates from domestic cases in 1995 and 1997, among which were the isolates from the fatal case and from the Tokyo case, and 15 isolates from imported (9 sporadic and 6 outbreak) cases in 19941995.

The $39 V$. cholerae $\mathrm{O} 1$ isolates could be classified into 12 temporary types by means of the two phenotypic methods and PFGE (Table 2). The causative isolate in the fatal case was typed as temporary type IV. This type is characterised by Celebes type prophage, streptomycin resistance and PFGE combination pattern CD. Nine other isolates were also placed in this group. These isolates were obtained from two domestic cases in 1995 and 1997 (from Tokyo in 1995 and Aichi in 1997) and seven imported cases (one from the Philippines in 1994 and three outbreak and three sporadic cases from Indonesia in 1995).

$\mathrm{CT}$ has been considered a major virulence factor of $V$. cholerae O1. However, CT production by the 37 toxigenic isolates evaluated by RPLA of two-fold serially diluted culture supernates (Table 3) revealed no

Table 2. Phenotypic and PFGE typing of $39 \mathrm{~V}$. cholerae $\mathrm{O} 1$ isolates

\begin{tabular}{|c|c|c|c|c|c|c|}
\hline \multirow[b]{2}{*}{ Type } & \multirow{2}{*}{$\begin{array}{l}\text { Year of } \\
\text { isolation }\end{array}$} & \multirow{2}{*}{$\begin{array}{l}\text { Prophage } \\
\text { type }\end{array}$} & \multirow{2}{*}{$\begin{array}{l}\text { Antibiotic } \\
\text { resistance } \\
\text { pattern }\end{array}$} & \multicolumn{2}{|c|}{ PFGE pattern } & \multirow{2}{*}{$\begin{array}{l}\text { Number of } \\
\text { isolates }\end{array}$} \\
\hline & & & & Not I & $S f i \mathrm{I}$ & \\
\hline I & 1989 & Celebes 'cured' & - & A & A & 4 \\
\hline II & 1989 & Celebes 'cured' & - & A & $\mathrm{B}$ & 1 \\
\hline III & 1993 & Celebes & SM, TMP & B & $\mathrm{C}$ & 1 \\
\hline IV & $1994-1995,1997$ & Celebes & SM & $\mathrm{C}$ & $\mathrm{D}$ & $10^{*}$ \\
\hline $\mathrm{V}$ & 1995,1997 & Celebes & - & $\mathrm{C}$ & $\mathrm{D}$ & 11 \\
\hline VI & 1984 & Classic-Ubon & - & $\mathrm{D}$ & $\mathrm{E}$ & 1 \\
\hline VII & 1984 & Classic-Ubon & - & $\mathrm{D}$ & $\mathrm{F}$ & 5 \\
\hline VIII & 1987 & Classic-Ubon & - & $\mathrm{E}$ & $\mathrm{G}$ & 1 \\
\hline IX & 1995 & Celebes 'cured' & - & $\mathrm{F}$ & $\mathrm{D}$ & 1 \\
\hline $\mathrm{X}$ & 1995 & Celebes & - & $\mathrm{F}$ & $\mathrm{D}$ & 1 \\
\hline XI & Before 1990 & Celebes & - & $\mathrm{G}$ & $\mathrm{D}$ & 2 \\
\hline XII & Before 1990 & Classic-Ubon & - & $\mathrm{H}$ & $\mathrm{D}$ & 1 \\
\hline Total & & & & & & 39 \\
\hline
\end{tabular}

SM, streptomycin; TMP, trimethoprim; PFGE, pulsed-field gel electrophoresis.

* Included the isolates from the fatal case and Tokyo. 
a

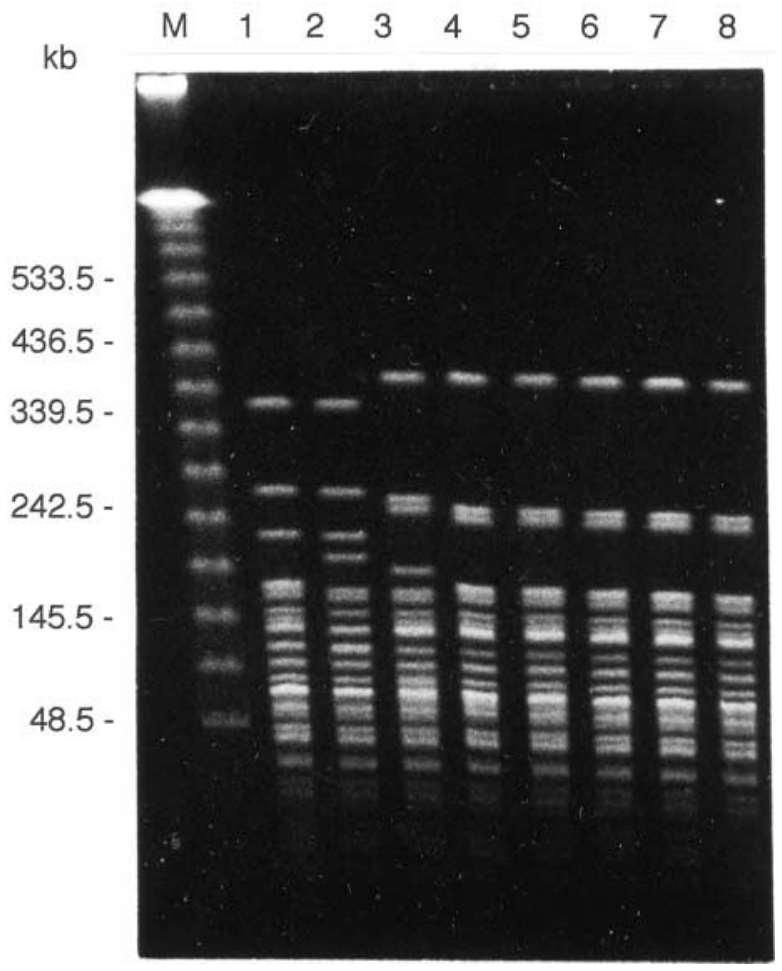

b

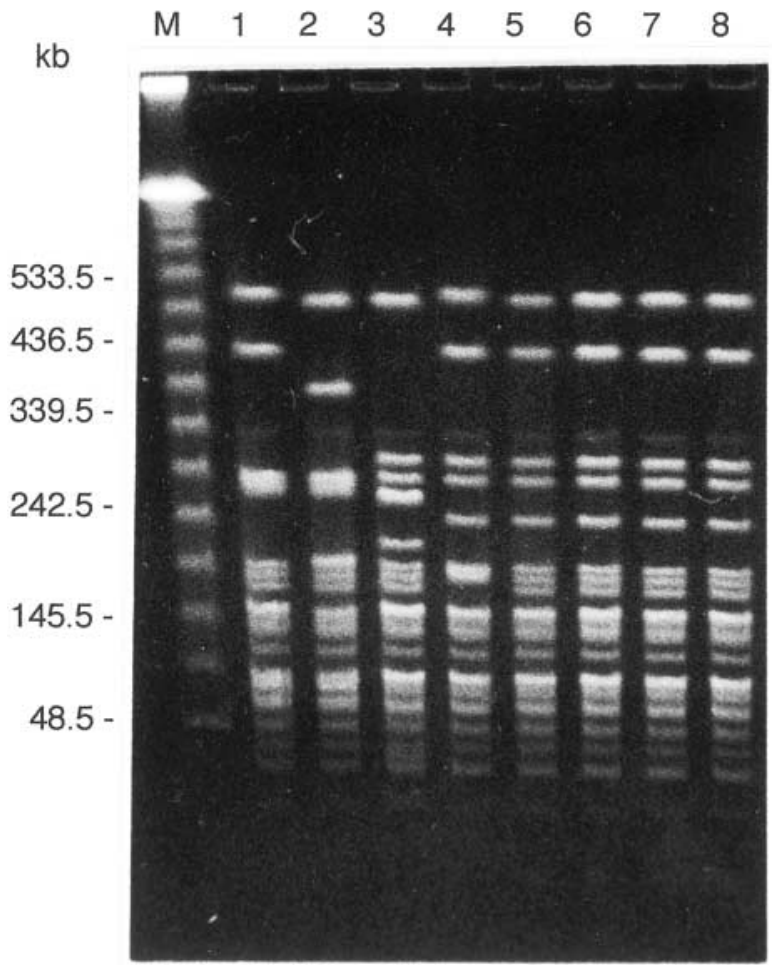

Fig. 1. Representative PFGE patterns of the V. cholerae O1 isolates from the domestic cases digested with NotI (a) and $S f i \mathrm{I}(\mathbf{b})$. Lanes 1 and 2, outbreak in Aichi in 1989; 3, 5-8, sporadic cases in Aichi in 1993, 1995, 1995 and 1997, and a fatal case of cholera in 1995; 4, sporadic case in Tokyo in 1995. (a) Lane M, molecular size markers; 1-3, PFGE patterns A1, A2 and B; 4-8, PFGE pattern C. (b) Lane M, molecular size markers; 1-4, PFGE patterns A, B, C and D1; 5-8, PFGE pattern D2.

Table 3. CT production by 37 toxigenic $V$. cholerae $\mathrm{O} 1$ isolates examined by RPLA

\begin{tabular}{lcc}
\hline Isolate from & $\mathrm{n}$ & CT production* \\
\hline Fatal case & 1 & $7.3(0.5)^{\dagger}$ \\
Mild infections and carrier & 36 & $7.1(2.5)^{\star}$ \\
\hline
\end{tabular}

* The values represent the maximum dilution $\left(\log _{2}\right)$ of the culture supernates in which CT expression was detected by RPLA.

${ }^{\dagger}$ The value was the mean (SD) of four different experiments.

*The value was the mean (SD) of 36 isolates.

significant difference between the isolate from the fatal case and the 36 isolates from mild cholera infections and a healthy carrier.

\section{Discussion}

Attempts have been made to detect possible genomic differences between clinical micro-organisms that cause severe and mild infections. Two research groups have reported no correlation between genetic properties and the outcome of group A streptococcal infection [13, 14]. On the other hand, analysis by flagella serotyping and PFGE of Salmonella typhi isolates from patients with severe and mild typhoid fever suggested an association between the typing pattern and the capability to cause severe illness $[15,16]$. In this study, phenotypic and PFGE analyses showed that the 10 temporary type IV $V$. cholerae $\mathrm{O} 1$ isolates from fatal and non-fatal infections between 1994 and 1997 had a remarkable homogeneity and there was no evidence that a distinctive clone was responsible for the fatal case of cholera. The result of an RPLA assay of CT was also consistent with this conclusion.

The temporary type IV isolates, including the isolate from the fatal infection, did not emerge in Aichi before 1993, suggesting that a new clone might have been introduced into this area after 1993 (Fig. 2). Although there is no firm epidemiological evidence that the carriage rate of the bacterium has increased among the residents since 1994, the temporary type IV isolates could have spread and disseminated into Aichi. This is consistent with the frequent isolation of the type among domestic cases of cholera in Aichi as well as imported cases between 1994 and 1997. Therefore, the introduction and dissemination of the new clone may have been an important step in triggering the fatal cholera infection.

Arakawa et al. analysed $67 \mathrm{~V}$. cholerae $\mathrm{O} 1$ isolates (36 domestic and 31 imported), which were isolated in separate parts of Japan in 1997, by comparing PFGE patterns of Not I- and Sfi I-digested chromosomal DNA. Of 67 isolates, 29 were assigned to a predominant pulse type, NotI-A1-Sfi I-A1. These isolates were also shared among domestic and imported cases of cholera 


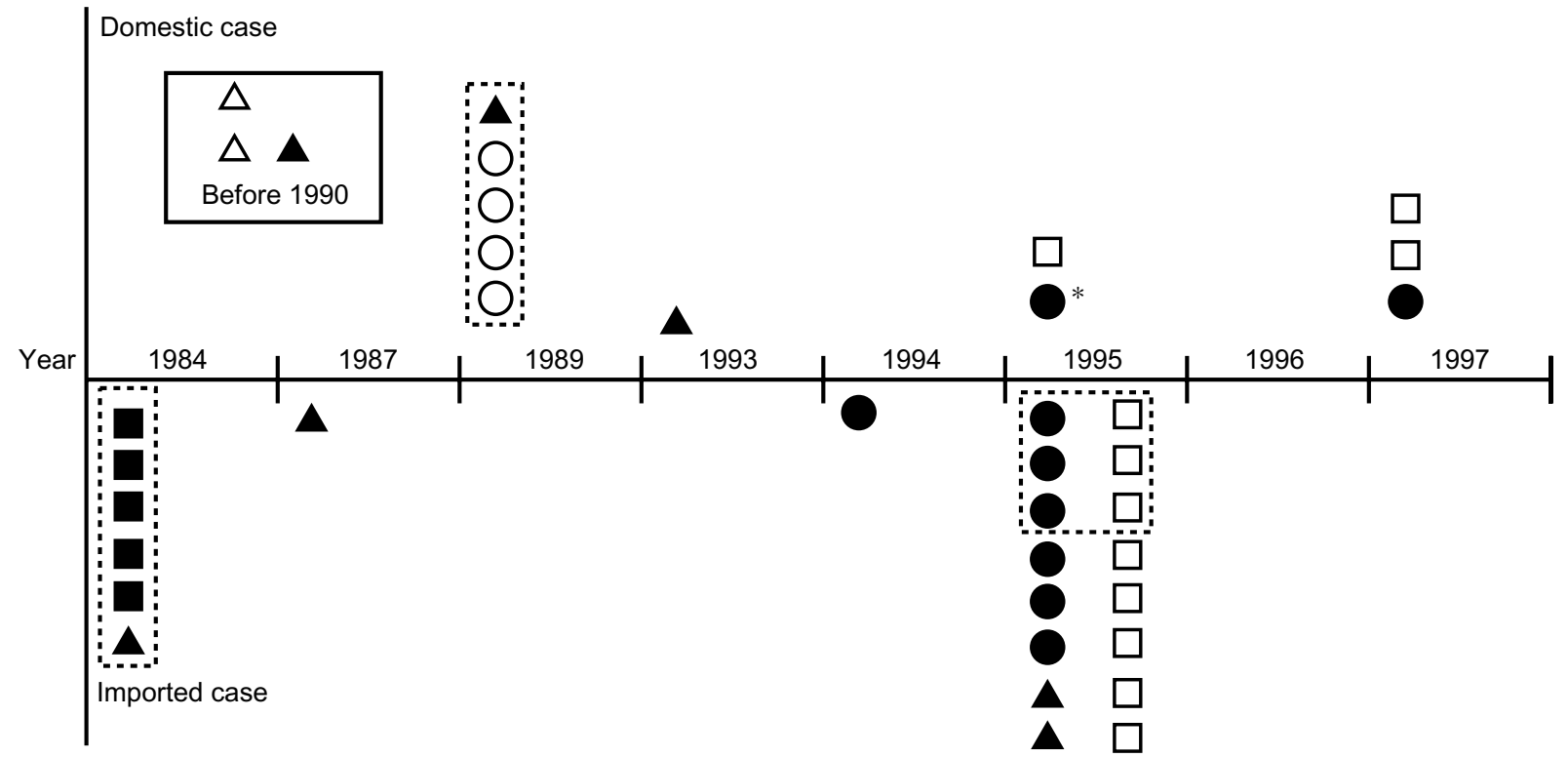

Fig. 2. Relationship between temporary type and the year of isolation of the 38 V. cholerae O1 isolates in Aichi: $\bigcirc$, type I; $\bullet$, type IV; $\square$, type V; $\mathbf{m}$, type VII; $\triangle$, type IX; $\boldsymbol{\Delta}$, others (types II, III, VI, VIII, IX, X and XII; these types each represented one isolate). Dot boxes represent $V$. cholerae $\mathrm{O} 1$ isolates from the same outbreaks. Box represents three $V$. cholerae $\mathrm{O} 1$ isolates from unknown cases before $1990 ;{ }^{*}$ indicates the isolate from the fatal case.

in Japan [17]. The current study showed that the temporary type IV isolates were also found in both domestic and imported cases during 1994-1995. The results of the present study and those of others suggest that the temporary type IV isolates could have been introduced into Aichi from countries where $V$. cholerae $\mathrm{O} 1$ is pandemic.

We thank the staff at Nagoya Airport Detached Office, Nagoya Quarantine Station, Aichi, and Sumio Yamada at Tokyo Metropolitan Research Laboratory of Public Health, Tokyo, Japan for providing $V$. cholerae $\mathrm{O} 1$ isolates.

\section{References}

1. Faruque SM, Albert MJ, Mekalanos JJ. Epidemiology, genetics, and ecology of toxigenic Vibrio cholerae. Microbiol Mol Biol Rev 1998; 62: 1301-1314.

2. National Institute of Infectious Diseases and Infectious Diseases Control Division, Ministry of Health and Welfare. Cholera, Japan, 1994-1995. Infect Agents Surveillance Rep 1996; 17: 71-72.

3. Dalsgaard A, Mortensen HF, Mølbak K, Dias F, Serichantalergs O, Echeverria P. Molecular characterization of Vibrio cholerae O1 strains isolated during cholera outbreaks in Guinea-Bissau. J Clin Microbiol 1996; 34: 1189-1192.

4. Takeya K, Shimodori S. "Prophage-typing" of El Tor Vibrios. J Bacteriol 1963; 85: 957-958.

5. Zinnaka H. [Kappa-type phage kensaho.] [In Japanese.] Rinsho-Kensa 1978; 22: 592-596.

6. National Committee for Clinical Laboratory Standards. Methods for dilution antimicrobial susceptibility testing for bacteria that grow aerobically. Villanova, PA, National Committee for Clinical Laboratory Standards, 1993.

7. Matsushita S, Yamada S, Kudoh Y, Ohashi M. [Drug-resistance and transferable $\mathrm{R}$ plasmids in Vibrio cholerae $\mathrm{O}-1$ and non
O-1, V. fluvialis and $V$. parahaemolyticus recently isolated from human sources.] [In Japanese.] Kansenshogaku-Zasshi 1987; 61: $109-117$.

8. Suzuki Y, Ishihara M, Matsumoto $\mathrm{M}$ et al. Molecular epidemiology of Salmonella enteritidis. An outbreak and sporadic cases studied by means of pulsed-field gel electrophoresis. J Infect 1995; 31: 211-217.

9. Cameron DN, Khambaty FM, Wachsmuth IK, Tauxe RV, Barrett TJ. Molecular characterization of Vibrio cholerae O1 strains by pulsed-field gel electrophoresis. J Clin Microbiol 1994; 32: 1685-1690.

10. Tenover FC, Arbeit RD, Goering RV et al. Interpreting chromosomal DNA restriction patterns produced by pulsedfield gel electrophoresis: criteria for bacterial strain typing. J Clin Microbiol 1995; 33: 2233-2239.

11. Berche P, Poyart C, Abachin E et al. The novel epidemic strain $\mathrm{O} 139$ is closely related to the pandemic strain O1 of Vibrio cholerae. J Infect Dis 1994; 170: 701-704.

12. Coelho A, Andrade JRC, Vicente ACP, Salles CA. New variant Vibrio cholerae $\mathrm{O} 1$ from clinical isolates in Amazonia. J Clin Microbiol 1995; 33: 114-118.

13. Muotiala A, Seppälä H, Huovinen P, Vuopio-Varkila J. Molecular comparison of group A streptococci of T1M1 serotype from invasive and noninvasive infections in Finland. J Infect Dis 1997; 175: 392-399.

14. Norgren M, Norrby A, Holm SE. Genetic diversity in T1M1 group A streptococci in relation to clinical outcome of infection. J Infect Dis 1992; 166: 1014-1020.

15. Grossman DA, Witham ND, Burr DH et al. Flagellar serotypes of Salmonella typhi in Indonesia: relationships among motility, invasiveness, and clinical illness. J Infect Dis 1995; 171: $212-216$.

16. Thong KL, Passey M, Clegg A Combs BG, Yassin RM, Pang T. Molecular analysis of isolates of Salmonella typhi obtained from patients with fatal and nonfatal typhoid fever. J Clin Microbiol 1996; 34: 1029-1033.

17. Arakawa E, Murase T, Matsushita S et al. Pulsed-field gel electrophoresis-based molecular comparison of Vibrio cholerae O1 isolates from domestic and imported cases of cholera in Japan. J Clin Microbiol 2000; 38: 424-426. 